\title{
Bicipital synovial cyst in poly-articular juvenile idiopathic arthritis
}

\author{
Kenza Bouayed*, Fenna El Founti, Asmaa Sakhi, Réda Taoussi, Zouhair Qechchar and Nabiha Mikou \\ Department of Pediatric Rheumatology, A. Harouchi University Children's Hospital, Morocco
}

\begin{abstract}
Background: Large synovial cysts are rare in juvenile idiopathic arthritis (JIA). They are usually located in popliteal area. Bicipital cyst is uncommon and has been described in systemic onset of JIA during an inflammatory attack. We describe the presentation and clinical course of bicipital synovial cyst occurring in patient with polyarticular subtype of JIA. In our knowledge, it's the first case reported.

Case presentation: Our patient had an active disease with high level of biological inflammation. After ruling out the infectious origin of the cyst, the diagnosis was confirmed by ultrasonography revealing a liquid nature of the formation and magnetic resonance imaging showing the continuity between the shoulder's joint effusion and the cyst. A complete resolution was obtained 4 weeks after control inflammation using high dose of anti inflammatory drugs (prednisone $1 \mathrm{mg} / \mathrm{kg} / \mathrm{d}$, indomethacin $3 \mathrm{mg} / \mathrm{kg} / \mathrm{d})$.

Conclusion: Bicipital cyst is an unusual condition of JIA, extremely rare in polyarticular form. His etiology remains poorly understood. Our Patient had a high level of biological inflammation as in systemic subtype. The diagnosis is confirmed by ultrasonography. Magnetic resonance imaging may be helpful in case of doubt. The treatment is no specific and based on the control of the disease activity. Even though bicipital cyst is rare manifestation of JIA, it should be considered as a complication of active disease related to inflammatory phenomena.
\end{abstract}

Abbreviation: JIA: Juvenile Idiopathic Arthritis ; JADAS: Juvenile Arthritis Disease Activity Score

\section{Background}

Synovial cysts are common in juvenile idiopathic arthritis (JIA). They are usually small, and preferentially located at the wrists and the popliteal region. Synovial cysts in other locations and/or with atypical extension are less common [1]. Bicipital involvement is a very rare condition of JIA. It occurs during an inflammatory attack phase. We describe on case in a child followed for polyarticular JIA diagnosed according to the Edmonton criteria [2].

\section{Case presentation}

This 9 years-old boy has been followed since the age of 7 for seronegative polyarticular juvenile idiopathic arthritis (negative rheumatoid factor, anti-citrullinated peptide antibodies and antinuclear antibodies) and treated with ibuprofen $40 \mathrm{mg} / \mathrm{kg} /$ day and methotrexate $0,5 \mathrm{mg} / \mathrm{kg} /$ week. Marked of swelling of the right arm without associated fever developed over a 1 month period of time and was initially thought to be a bacterial or mycobacterial soft tissue abcess. Doppler ultrasound demonstrates cystic structure with echoic content measuring $60 \times 32$ $\mathrm{x} 25.5 \mathrm{~mm}$ (Figure 1) without an associated joint effusion. The structure was aspirated, and a purulent fluid was extracted that contained many neutrophils and led to the resolution of the swelling. The Gram stain of the fluid was negative for any organism and the cultures were sterile. Further laboratory evaluation was notable for a sedimentation rate of $56 \mathrm{~mm}, \mathrm{C}$ reactive protein of $256 \mathrm{mg} / \mathrm{l}$, and platelet count of 795000 elements / $\mathrm{mm} 3$. The tuberculin skin test and QuantiFERON assay were negative. A 10 day course of antibiotic therapy with ampicillin /sulbactam and amikacin was given. The swelling recurred after 15 days of completing the antibiotic therapy and the diagnosis of abscess was favored over that of a bicipal synovial cyst based on the magnetic resonance imaging findings (Figure 2) which showed a cystic formation of the superficial soft tissues in continuity with an articular effusion shoulder that was not visualized on ultrasound imaging studies. A biopsy was performed. The pathology report was consistent with cystic fibrous formation containing mononuclear inflammatory elements that is lined by flattened regular unistratified epithelium consistent with a bicipital cyst. The patient was treated with indomethacin $3 \mathrm{mg} /$ $\mathrm{kg} /$ day and prednisone $1 \mathrm{mg} / \mathrm{kg} /$ day with a tapering regimen and followed by maintenance of methotrexate. This led to to complete involution of the cyst within a 4 week period of time. 19-months after initial presentation the presence of extensive joint involvement was noted and the medication regimen was intensified with the addition of etanercept and tocilizumab, as well as intra-articular infiltration of the right knee with triamcinolone hexacetonide. This treatment, allowed a normalization of the inflammatory balance and a partial remission with a Juvenile Arthritis Disease Activity Score JADAS 27 at 15.5, estimated at the onset of illness at 22.4.

${ }^{\star}$ Correspondence to: Bouayed Kenza, Department of Pediatric Rheumatology, A. Harouchi University Children's Hospital, Ibn Rochd, Mo-hamed El Fidouzi Street ex Jenner, Kergomard Street, Bay View Residence, A3, Ain Diab, Casablanca, Morocco, 20 052, Tel: +212 6613107 74; E-mail: bouayedkenza@ hotmail.com

Key words: bicipital cyst juvenile arthritis

Received: February 21, 2019; Accepted: March 22, 2019; Published: March 27, 2019 


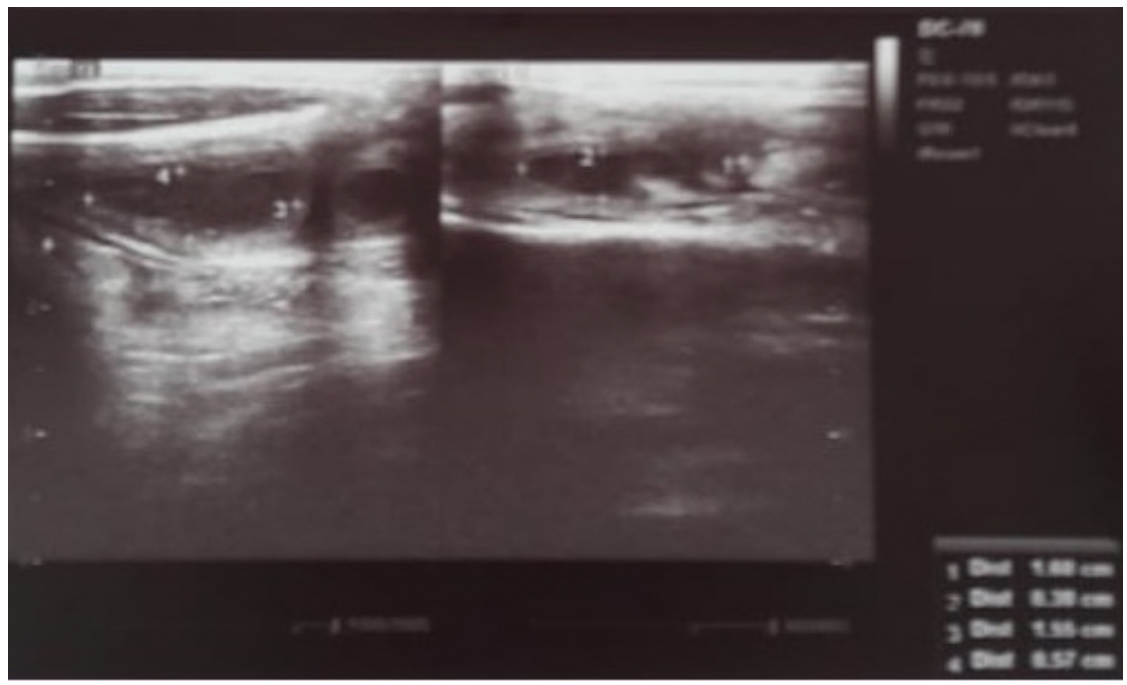

Figure 1. Ultrasound of right arm. A well limited formation with finely echoic content measuring $60 \times 32 \times 25.5$ mm, with posterior reinforcement (Red arrow)
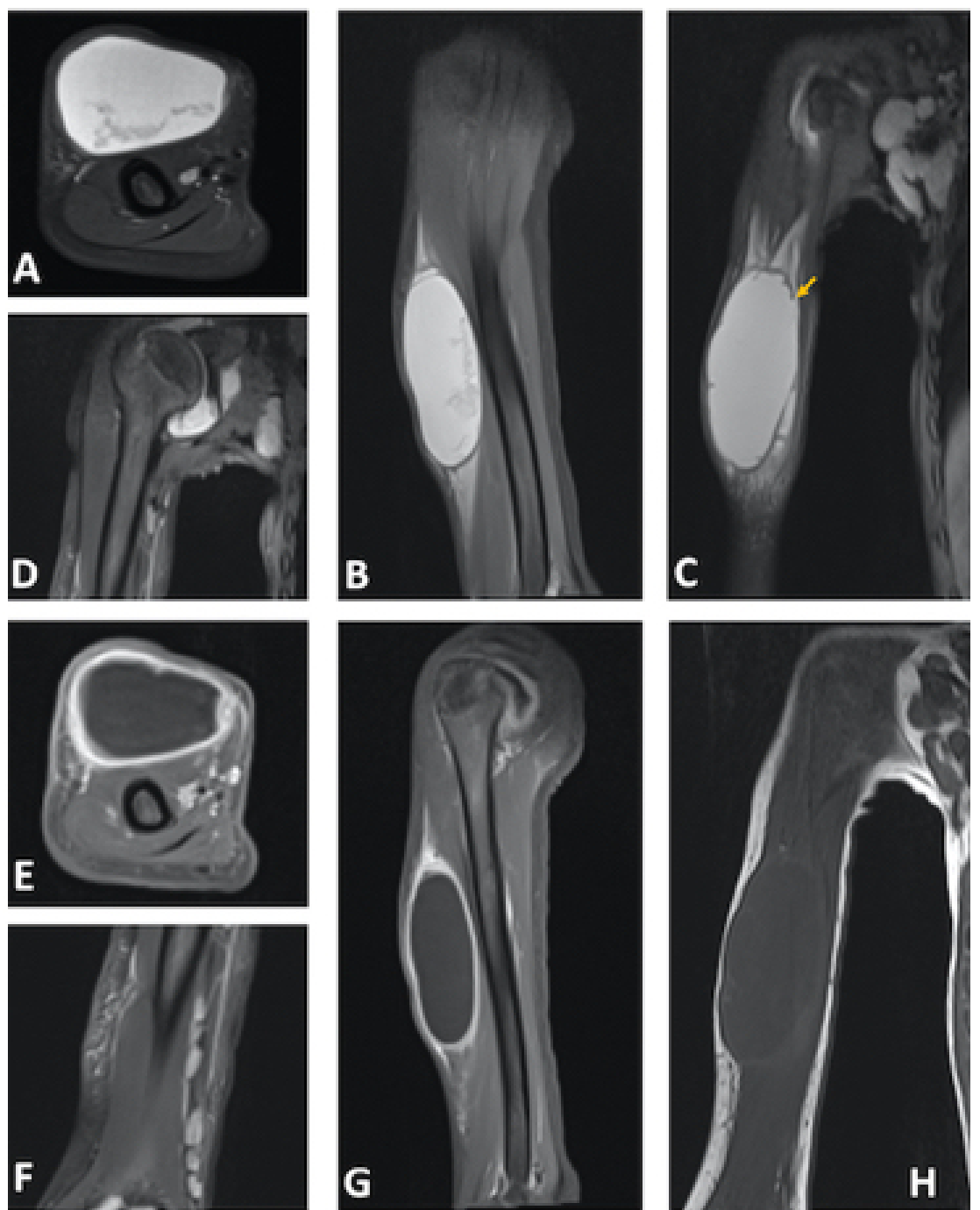

Figure 2. MRI of right arm. Cystic formation of the soft tissues of the anterior oblong right angle brachial box, well defined, with T1 hyposignal content (A), with T2 hypersignal (B). This formation communicates with the joint and with the articular effusion of the shoulder (C) via late posterior superior limb (yellow arrow), associated with axillary and para-diaphysial cysts (D). Gleno-humeral synovial thickening is associated with contrast enhancement after gadolinium injection (E) 


\section{Discussion and conclusions}

A bicipital cyst is a rare condition seen in patients with juvenile idiopathic arthritis (JIA) in contrast to other more common synovial cysts $[1,3]$. Only 15 cases have been published in the literature since 1978 [3-8]. It occurs most commonly in an inflammatory context of systemic JIA $[3,5]$ as noted in reported cases above $[3,5,7,8]$. This case is unusual in that this patient is the first case of a bicipital cyst with underlying polyarticular JIA. This such complication can be confounded with tumors or soft tissues infections leading to rule out all the diagnosis be supposed as it has been done in our case [1]. The etiology of the bicipital cyst formation remains poorly understood. Two hypotheses are suggested including the presence of a synovial effusion from the adjacent joint through the bicipital tendon sheath following a rupture or production in situ by the membrane lining the sheath of the bicipital tendon after its extension from the synovial joint during an inflammatory phase [3,9]. Our patient's lesion is likely related to the first hypothesis given the presence of the effusion of the shoulder and the continuity gap highlighted on the MRI. In both clinical scenarios, a good response to the various drugs with anti-inflammatory effects and the absence of constitution during the remission phase suggest the role of pro-inflammatory cytokines in the genesis of this complication. Control of the JIA activity appears to be the leading means by which to treat this finding.

\section{Declarations}

\section{Consent for publication}

Not applicable

\section{Availability of data and material}

All data generated or analysed during this study are included in this published article [and its supplementary information files].

\section{Competing interests}

The authors declare that they have no competing interests in this section.

\section{Funding}

Not applicable

\section{Authors contributions}

$\mathrm{KB}$ is the major writer of the manuscript and the referent rheumatologist of the patient. FE is the resident who followed up the patient in the day hospital. AS is a permanent pediatrician working in the Pediatric Rheumatology unit. ZQ and RT performed US for the patient, analyzed and choosed the right MRI pictures. NM is the head of the Pediatric Rheumatology unit.

\section{Acknowledgments}

We thank doctor Benyahya radiologyist in the liberal sector " Maarif Radiology Center. 16-17 rue Mohamed Bahi, ex Meissonnier street, Casablanca, Morocco » for performing the MRI which was broken at this period in our hospital.

\section{References}

1. Roth J, Scheer I, Kraft S, Keitzer R, Riebel T (2006) Uncommon synovial cysts in children. Eur J Pediatr 165: 178-181. [Crossref]

2. Petty RE, Southwood TR, Manners P, Baum J, Glass DN, et al (2001) International League of Associations for Rheumatology classification of juvenile idiopathic arthritis: second revision, Edmonton, 2001. J Rheumatol 31: 390-392. [Crossref]

3. Shimizu M, Yokoyama T, Wada T, Yachie A (2010) Bicipital synovial cyst in systemiconset juvenile idiopathic arthritis. J Pediatr 157: 168. [Crossref]

4. Bamzai A, Krieger M, Kretschmer RR (1978) Synovial cysts in juvenile rheumatoid arthritis. Annals of the Rheumatic Diseases 37: 101-103. [Crossref]

5. Bloom BJ, Tucker LB, LC Miller, McCauley RG, Schaller JG (1995) Bicipital synovial cysts in juvenile rheumatoid arthritis: clinical description and sonographic correlation. J Rheumatol 22: 1953-1955. [Crossref]

6. Dell'Era L, Vercellesi P, Forzenigo LV, Carnelli V, Corona F (2008) Synovial cyst in juvenile idiopathic arthritis. Clin Rheumatol 27 Suppl 2: S43-45. [Crossref]

7. Costello PB, Kennedy AC, Green FA (1980) Shoulder joint rupture in juvenile rheumatoid arthritis producing bicipital masses and a hemorrhagic sign. $J$ Rheumatol; 7: 563-566. [Crossref]

8. Mizuta M, Shimizu M, Nakagishi Y, Kasai K, Yachie A (2017) Bicipital synovial cyst associated with systemic juvenile idiopathic arthritis: new insights obtained from unique pathological findings. Int J Rheum Dis 20: 2242-2244. [Crossref]

9. Doube A, Gow PJ (1987) Bicipital swelling in adult-onset Still's disease. $\mathrm{Br} J$ Rheumatol 26: 216-217. [Crossref]

Copyright: (C2019 Bouayed K. This is an open-access article distributed under the terms of the Creative Commons Attribution License, which permits unrestricted use, distribution, and reproduction in any medium, provided the original author and source are credited. 